\title{
O CONHECIMENTO COMO INSTRUMENTO DE TRABALHO DA ENFERMAGEM ${ }^{1}$
}

\author{
[Knowledge as a work tool for nursing]
}

Maria Elisabeth Cestari*

RESUMO: o artigo apresenta uma reflexão teórica sobre o saber como instrumento de trabalho, e sua articulação com o objeto e finalidades do trabalho de enfermagem. Neste sentido, inicialmente é apresentada uma breve revisão sobre as características do processo de trabalho, seguida de uma discussão do saber como um instrumento de trabalho e da necessidade de sua adequação ao objeto e finalidade do trabalho. Finalizando são apresentadas algumas considerações sobre o ensino da enfermagem, em particular das enfermeiras, e suas respostas às necessidades da profissão.

PALAVRAS-CHAVE: Teoria de enfermagem; Conhecimentos; Atitudes e prática.

\section{INTRODUÇÃO}

No Brasil a estruturação da enfermagem como uma atividade sistematizada, que exige ensino formal e regulada por legislação específica, data do início do século XX. A criação da Escola de Enfermeiras Ana Néri, em 1923, é freqüentemente citada como um marco na formação profissional de enfermagem não só por ser a primeira escola dirigida por enfermeiras, como por servir de modelo para o desenvolvimento das escolas de enfermagem em nosso país.

A Escola de Enfermeiras Ana Neri foi criada em um contexto político-institucional que demandava profissionais para atender aos problemas de saúde pública enfrentados no Brasil. Foi organizada e dirigida por um grupo de enfermeiras americanas que seguiam o modelo Nightingale de formação. Tinha como objetivos formar profissionais que servissem de elemento de ligação entre o atendimento médico institucional e o domicílio dos pacientes, administrassem a assistência

1 Trabalho apresentado à disciplina de Processo de Trabalho em Saúde e Enfermagem do Programa de Pós-Graduação em Enfermagem da Universidade Federal de Santa Catarina.

* Enfermeira. Professora do Departamento de Enfermagem da Fundação Universidade Federal do Rio Grande. Doutoranda do Programa de Pós-Graduação em Enfermagem da Universidade Federal de Santa Catarina. de enfermagem e formassem pessoal auxiliar e novos enfermeiros. Em 1931, esta escola foi considerada padrão, servindo de modelo para todas as outras (PIRES, 1989).

A implantação da Escola Ana Néri foi importante por ter orientado o desenvolvimento do ensino de enfermagem no nosso país e, em conseqüência, teve um impacto significativo na estruturação da enfermagem como profissão. A escola é o local de apropriação e reprodução do conhecimento, tendo ainda a função de formar trabalhadores para o exercício de determinadas funções. Além disso, o trabalho de pesquisa e a produção de conhecimentos tem estado tradicionalmente ligado à escola, em particular à pós-graduação.

O desenvolvimento técnico-científico na enfermagem, segundo Rosa et al (1989), teve seu início formal em 1963 com a produção da primeira tese. Na década de 60 consta dos catálogos do CEPEn² um total de 04 trabalhos, na década de 70, estão catalogados 154 trabalhos e na década de 80, (até 88) 349. No período de 1972 a 1999 foram defendidas e publicadas nos catálogos do CEPEn, 376 teses de doutorado (SILVA; RAMOS, 2001).

Apesar dos avanços conseguidos desde sua institucionalização, a enfermagem ainda enfrenta uma série de dificuldades e desafios. Uma das questões que permanece controversa é o que é a enfermagem: um trabalho? uma profissão? uma ciência? uma disciplina? uma arte? tudo isto?

Inicialmente, a enfermagem foi apresentada como uma arte, posteriormente, em busca de reconhecimento, passou a ser caracterizada como uma profissão e/ou ciência e, mais recentemente, surge a discussão, bastante restrita aos meios acadêmicos, da enfermagem como disciplina. Esta pode parecer uma questão meramente semântica para alguns, mas pessoalmente acredito que a forma como vemos a enfermagem condiciona a forma como a praticamos, ensinamos, estudamos, pesquisamos e, acima de tudo, condiciona a forma como nos percebemos e ao nosso fazer.

Fonte de dados os catálogos do CEPEn, volumes I a VIII. 
Observando a literatura produzida na área, parece haver um certo consenso, atualmente, de que o cuidado caracteriza o trabalho da enfermagem constituindo-se no foco de estudos para a produção de conhecimentos que constituem a enfermagem enquanto disciplina.

No entanto, não é somente a discussão interna que delimita a enfermagem, como se ela existisse num mundo próprio. O que a sociedade, em seus diversos segmentos, acredita ser a enfermagem condiciona o que é esperado e o que é exigido das profissionais de enfermagem. As instituições empregadoras acreditam que enfermeiras, técnicas e auxiliares de enfermagem devem realizar algumas atividades específicas, e exigem a sua realização. A população atendida tem certas expectativas relacionadas aos profissionais da saúde e avalia, cobra e solicita atenção de acordo com estas expectativas, valorizando e hierarquizando o trabalho dos diferentes profissionais. ${ }^{3}$ Assim, a forma como somos percebidas se reflete na forma como nos percebemos e condiciona nossas possibilidades e limites.

No presente texto, a enfermagem será considerada como um trabalho, uma prática social que é, portanto, historicamente estruturada e socialmente articulada. Este trabalho pretende ser uma reflexão teórica inicial sobre o saber como instrumento de trabalho, e sua articulação com o objeto e finalidades do trabalho de enfermagem. Neste sentido, inicialmente será apresentada uma breve revisão sobre o processo de trabalho seguida de uma discussão do saber como um instrumento de trabalho e a necessidade de sua adequação ao objeto e finalidade do trabalho. Finalizando são apresentadas algumas considerações sobre o ensino da enfermagem, em particular das enfermeiras, e suas respostas às necessidades da profissão.

\section{O PROCESSO DE TRABALHO DA ENFERMAGEM}

O trabalho humano, abstratamente concebido, é a aplicação de uma FORÇA DE TRABALHO sobre um OBJETO, com a utilização de INSTRUMENTOS, que resulta num PRODUTO cuja FINALIDADE já foi determinada. O trabalho visa transformar algo extraído da natureza para atender a uma necessidade, caracterizando-se como propriamente humano pelo fato de ser primeiramente idealizado na imaginação do trabalhador (MARX, 1982).

Os elementos do processo de trabalho estão interligados já que o objeto de trabalho deve ser adequado à

\footnotetext{
Geralmente a população, quando pensa em serviços de saúde, solicita assistência médica por ser este profissional que é representado como aquele capaz de resolver os problemas de saúde, ou seja "tratar as doenças". Aquilo que a população espera é aquilo que ela cobra, o que tem algum efeito nas decisões a respeito das políticas de saúde.
}

finalidade proposta, os meios devem ser adequados ao objeto e finalidade e o produto final precisa satisfazer à necessidade que deu origem ao próprio processo de trabalho. "O trabalho é um processo constituído de momentos que se iluminam reciprocamente e têm uma posição relacional" (ALMEIDA; ROCHA, 1989, p. 23).

A partir da década de 80 , surgiram vários estudos que enfocaram a enfermagem como um trabalho possibilitando macroanálises, particularmente, de sua gênese e evolução histórica no Brasil (ALMEIDA; ROCHA, 1997).

Concebendo a enfermagem como um trabalho, é necessário, inicialmente, determinar qual é o seu objeto e finalidade para, a partir daí, construir os instrumentos de trabalho apropriados. No entanto, apesar dos estudos realizados, parece não haver consenso entre as profissionais sobre qual seja seu objeto de trabalho. Em um estudo de caso, Argenta (2000) observou que as trabalhadoras de enfermagem tem dificuldade de identificar a finalidade e o objeto de seu trabalho, o que dificulta sua compreensão sobre a profissão.

$\mathrm{Na}$ análise das temáticas dos Congressos Brasileiros de Enfermagem (CBEns), da década de 80, o cuidado de enfermagem, o processo administrativo e a educação em saúde aparecem como objetos de trabalho (ALMEIDA et al.,1989). Da mesma forma, o cuidado é apresentado, como finalidade e instrumento, em diferentes situações e por diferentes autores.

A enfermagem é um trabalho complexo, desenvolvido de forma coletiva com outros profissionais da área da saúde. Deste ponto de vista as pessoas "com seu corpo, sua consciência e suas relações são os objetos finais das ações dos profissionais de saúde", sendo que a finalidade do trabalho da enfermagem é "o atendimento às necessidades das pessoas, através da ação de cuidar" (LEOPARDI et al., 2001, p.36).

Ainda de acordo com as mesmas autoras, o processo de trabalho da enfermagem pode ser dividido em três, cada um com objetos e instrumentos distintos, embora com a mesma finalidade geral: o processo de cuidar, que tem como objeto o corpo, ${ }^{4}$ o processo de gerenciar, cujo objeto é a organização do trabalho em si e o processo de educar, que tem como objeto a consciência individual e coletiva. Cada um destes objetos exige o desenvolvimento e utilização de instrumentos específicos, apropriados à sua apreensão e manipulação.

O corpo não entendido de forma restrita mas como um "objeto animado, que tem uma natureza física e social", "um corpo que não se quer ver partido, mas inteiro e humano" (Leopardi et alli, 2001, p. 38/39) 
Considerando o trabalho concreto, tal como é vivido nas diferentes instituições de saúde no nosso país, é impossível negar que o gerenciamento da assistência, e dos próprios serviços, é parte fundamental do trabalho das enfermeiras. No entanto, a negação das atividades de gerenciamento, e a sensação de culpa pelo afastamento do cuidado direto dos pacientes, é uma constante entre as enfermeiras. Desta forma, o processo de gerenciar não é tranqüilamente aceito como legítimo na enfermagem.

É relativamente fácil distinguir as finalidades e objetos dos processos de cuidar e de gerenciar, mas pessoalmente acho difícil separar a educação para a saúde do processo de cuidar e, conseqüentemente seus objetos. Se cuidar é um todo integrado, no qual não é possível separar o efeito do processo, então uma de suas facetas é a educativa. A educação faz parte do processo de cuidar, que é em si mesmo educativo. Na minha prática docente tenho visto que esta separação entre cuidar e educar tem, de um modo geral, reduzido tanto o cuidado quanto a educação à condição de procedimentos estanques que só compartimentalizam o ser cuidado, reforçando a divisão do cliente que, no discurso, deve ser visto como um todo.

Talvez seja possível fazer uma distinção entre a educação em saúde, dirigida aos clientes, e outras atividades educativas, como a educação continuada e a formação profissional. A educação, em saúde, tem como finalidade construir com o cliente sua autonomia quanto a própria saúde, é a educação formal tem como objetivo construir os conhecimentos e habilidades necessários para o exercício da profissão.

No entanto, mesmo na área da educação formal já surgem propostas, como a de GEIB (2000), de unir educação e cuidado num mesmo processo, considerando que não se pode ensinar a cuidar, sem, ao mesmo tempo, cuidar dos sujeitos deste processo. Neste caso, seria necessária a utilização de um mesmo instrumento nos processos de cuidar e educar.

Para desenvolver seu trabalho a enfermagem necessita de instrumentos apropriados. Instrumento ou meio de trabalho é "uma coisa, ou complexo de coisas, que o trabalhador insere entre si mesmo e o objeto de trabalho e lhe serve para dirigir a atividade sobre este objeto" (MARX, 1982, p.203). Em sentido lato, todas as condições materiais para a realização de um trabalho, a Terra como habitat, os prédios e as estradas, são meios de trabalho.

A fabricação de instrumentos de trabalho é uma característica humana, ou seja, o ser humano idealiza e constrói instrumentos que possibilitem, tornem mais fácil e mais eficiente a transformação do objeto de trabalho no produto idealizado. "O que distingue as diferentes épocas econômicas não é o que se faz, mas como, com que meios de trabalho se faz. Os meios de trabalho servem para medir o desenvolvimento da força humana de trabalho e além disso, indicam as condições sociais em que se realiza o trabalho" (MARX, 1982, p. 204).

\section{A ENFERMAGEM E SEUS INSTRUMENTOS DE TRABALHO}

Como foi afirmado, os diferentes componentes do processo de trabalho são interdependentes e, portanto, não é possível pensar os instrumentos de trabalho sem relacioná-los ao objeto e às finalidades. Os instrumentos de trabalho devem possibilitar a ação sobre um objeto específico de forma que o resultado seja um produto que atenda a finalidade desejada.

A sofisticação e diversificação dos instrumentos de trabalho é uma das características do mundo contemporâneo e torna possível a realização do até então impensável, como a clonagem de seres humanos. Além disto, o desenvolvimento atual dos instrumentos de trabalho cada vez mais permite a substituição do próprio trabalho humano, gerando desemprego.

Os instrumentos de trabalho podem ser divididos em duas espécies: os que permitem a apropriação inicial do objeto, o que corresponde ao aspecto mais intelectual do trabalho; os que permitem a transformação física do objeto, que corresponde à dimensão manual do trabalho. Assim, são instrumentos os equipamentos, as máquinas, utensílios, o saber, os métodos, as tecnologias.

Os instrumentos materiais utilizados pela enfermagem, (instrumental, equipamentos, mobiliário, ...) pertencem às instituições de saúde empregadoras que, teoricamente, deveriam disponibilizar condições materiais em quantidade e qualidade adequada para a realização do trabalho. Sabe-se que, na maior parte das vezes, tal não acontece, o que tem gerado nas próprias trabalhadoras sentimentos de insatisfação, de impotência e, algumas vezes, de responsabilidade pessoal por esta situação.

O saber como instrumento de trabalho é o que possibilita ao trabalhador apreender o objeto já que "o objeto não se impõe em nenhum caso naturalmente, mas corresponde já a um olhar enviesado que nele discrimina a potencialidade do produto" (GONÇALVES, 1994, p.62).

ALMEIDA e ROCHA (1989) ao estudarem o saber da enfermagem, apontaram as técnicas de enfermagem, os princípios científicos e as teorias de enfermagem como as expressões mais significativas deste saber e a escola como a instituição que se apropria e reproduz este saber. Pode-se afirmar que, atualmente, a enfermagem continua se utilizando fundamentalmente das técnicas e dos princípios científicos como instrumentos de trabalho. 
$\mathrm{Na}$ análise das temáticas dos CBEns dos anos 80, surge a questão da competência política como instrumento necessário para o trabalho da enfermagem, discurso que ganhou força na década de 90, tornando-se hegemônico na área de ensino. $O$ impacto deste posicionamento na formação e atuação profissional ainda necessita ser investigado.

As teorias de enfermagem, na última década, foram mais divulgadas e estudadas havendo um movimento importante no sentido de caracterizar o cuidado como a essência da profissão. No entanto, estas teorias ainda não se tornaram um instrumento de trabalho efetivo na prática profissional. A questão da influência de seus conceitos na percepção das enfermeiras sobre o próprio trabalho ainda precisa ser respondida.

ARGENTA (2000) constatou, num estudo de caso, que as enfermeiras identificaram, como instrumento de trabalho, a supervisão, orientação e planejamento; a conversa, simpatia, bom humor; a equipe; a tecnologia; os meios materiais. As outras trabalhadoras da enfermagem identificaram o diálogo, desenvolvimento de técnicas de enfermagem; todo material utilizado nas técnicas e a própria força de trabalho.

A conversa, simpatia, bom humor podem ser entendidos como características da força de trabalho, mas também podem ser entendidos como formas de ser que possibilitam o cuidado. O diálogo, na verdade, é um aspecto muito valorizado nas teorias de enfermagem.

As teorias de enfermagem começaram a surgir em meados da década de 60, nos Estados Unidos, e tiveram como objetivo geral a humanização da assistência ou cuidado de enfermagem, criticando a transformação do paciente em objeto e buscando a independência em relação à medicina (WALDOW, 1998).

À medida que foram se desenvolvendo as teorias, observa-se que o saber volta-se para o cuidado do paciente, distanciando-se da cura como finalidade do trabalho da enfermagem. Esta mudança de concepção, da cura para o cuidado, deveria levar à criação de novos instrumentos de trabalho.

É necessário lembrar que a criação de novos instrumentos não garante sua utilização pois, para tal, é necessário que estes instrumentos sejam apropriados pelo empregador e pelo próprio trabalhador. Em outras palavras, teorias de enfermagem, tecnologias e outros instrumentos criados pelas profissionais de enfermagem só poderão ser utilizados na prática se existirem condições materiais concretas para isso. Como na imensa maioria dos casos, a enfermagem é assalariada em instituições de saúde, os instrumentos por ela criados precisam ser aprovados e incorporados pela instituição.
As teorias do cuidado, por exemplo, que prevêem uma maior interação entre cliente e enfermeira, de um modo geral, exigem um quantitativo maior de pessoal, o que pode não ser de interesse da instituição. "Nenhum instrumento de trabalho será utilizado se encarecer o processo de trabalho" (ROSA et al., 1989, p.103).

Também é necessário lembrar que a instituição de saúde, como empregadora, determina as atividades que devem ser desenvolvidas pelos profissionais que contrata, $\mathrm{e}$ que, especialmente os hospitais, teoricamente tem como objetivo o tratamento e cura de doenças e, para esta finalidade, o trabalho médico aparece como fundamental. Neste sentido, o trabalho de enfermagem aí realizado, do ponto de vista da instituição, deve ser voltado para o suporte ao trabalho médico, para permitir o tratamento e cura das doenças.

Os métodos propostos pela enfermagem, especialmente os que têm sua origem nas teorias de enfermagem, em geral, ou exigem pessoal mais capacitado ou maior número de pessoal ou prolongam o tempo de trabalho. Deste ponto de vista, ao analisarmos a utilização ou não das teorias de enfermagem na prática, é preciso considerar não só os fatores internos à profissão (como qualidade da formação), mas também as condições materiais concretas para a realização do trabalho.

A questão se torna ainda mais complexa no sistema dominante que tem valores diferentes dos valores da profissão. O que as instituições, de um modo geral, desejam? Que o paciente seja cuidado como um todo ou que tenha alta o mais precocemente possível? Ou que a internação não cause prejuízo financeiro, independentemente do seu resultado para o paciente?

Segundo ROSA et al. (1989), nos serviços de saúde a contratação de trabalhadores se dá em qualidade e quantidade mínimas para não causar prejuízos visíveis e a população não consegue avaliar o risco a que está submetida. Se isto era verdade no fim dos anos 80 , parece ser mais verdadeiro no momento atual com a precarização do atendimento à saúde da população em geral.

Estas dificuldades não implicam que a categoria deva simplesmente se adaptar ${ }^{5}$ ao mercado de trabalho, mas antes, que precisa encontrar instrumentos que lhe permitam o enfrentamento deste mercado. "O trabalho científico explora a realidade e cria novos instrumentos de trabalho, num avanço quantitativo e qualitativo, para expor as condições de realizar o projeto de liberdade da humanidade" (ROSA et al., 1989).

Paulo Freire (1991) afirma que adaptação está ligada à acomodação, perda de liberdade, enquanto integração implica em ajustar-se a sociedade e transformá-la ser crítico. 
LUNARDI FILHO (1998), por exemplo, levanta a tese de que a hospitalização ocorra devido à necessidade de implementação da terapêutica e de cuidados que não podem ser prestados pelos familiares e que, no hospital, são desenvolvidos pela enfermagem. Assim, a necessidade de hospitalização decorreria da carência dos cuidados de enfermagem. Esta é uma idéia que indica uma nova interpretação do trabalho e que pode ser explorada.

A formação das profissionais, nas temáticas dos CBEns na década de 80, aparece como exercendo papel fundamental na transformação da prática, existindo maior preocupação com a educação formal do que com educação continuada (ALMEIDA et al., 1989). Esta posição reflete primeiramente uma idealização do papel da escola na sociedade, pois a formação sozinha não pode mudar as condições sociais, embora seja indispensável para que estas mudanças ocorram. Quanto à educação continuada, podese levantar a hipótese que o seu desenvolvimento sofre as mesmas dificuldades e impedimentos da prestação de cuidados uma vez que depende da disponibilização de recursos por parte da instituição empregadora.

O caminho da formação profissional é difícil de ser trilhado e exige uma avaliação constante para que se evite de um lado a idealização excessiva e, de outro, o simples treinamento de mão de obra para o mercado. Talvez, a proposta de formar profissionais críticos e reflexivos, tenha ganho destaque no discurso educativo atual justamente por permitir uma aproximação entre o idealizado e o possível no momento. É claro que é indispensável lembrar que a crítica e a reflexão não se dão no vazio, mas em situações concretas, envolvendo temas específicos.

\section{A FORMAÇÃO DE ENFERMAGEM}

Atualmente a enfermagem está vivendo uma fase de discussão e questionamento de seu saber, sendo clara a tendência por uma abordagem mais humanista (WALDOW, 1998). Questionar o saber da enfermagem implica questionar qual é sua finalidade e seu objeto.

Esta discussão não pode ser limitada à academia, devendo envolver todas as categorias profissionais, no entanto, como a escola tem como objeto específico o "instrumental saber" lhe cabe papel importante neste processo.

Analisando a formação das enfermeiras no Brasil, observa-se que esta já iniciou com uma contradição, utilizar longas horas de aprendizado no hospital para formar enfermeiras que deveriam trabalhar basicamente em saúde pública, no gerenciamento da assistência e no ensino. Devese notar que, utilizando a escola Ana Neri como modelo, o ensino de enfermagem desenvolveu-se de acordo com o modelo americano do sistema nightingale, ou seja, com pequena carga teórica e ênfase nas atividades práticas.

$\mathrm{Na}$ proposta de Nightingale, as enfermeiras eram responsáveis pelo ensino de enfermagem e as escolas deviam possuir autonomia pedagógica, sendo a parte teórica lecionada por médicos e a supervisão da prática feita pelas "sisters". Nos Estados Unidos houve uma adaptação deste modelo com as escolas sendo atreladas aos hospitais, sem autonomia pedagógica e com uma redução significativa da parte teórica do curso. Na verdade, o trabalho das estudantes de enfermagem supria as necessidades de mão de obra hospitalar com baixíssimo custo.

Até a década de 1930-40 não há produção de conhecimentos teóricos ou elaboração de instrumentos abstratos para a apreensão do objeto, mas apenas de princípios de organização, o que respondia às necessidades dos empregadores e mesmo a origem da enfermagem moderna. A partir dos anos 50, aproximadamente, os estudos na área de enfermagem voltaram-se para as questões da educação, o que reflete a crença de que a melhor formação leva à melhor prática (ALMEIDA e ROCHA, 1989).

De acordo com MELEIS (1991), as primeiras elaborações teóricas da enfermagem foram feitas por Nightingale no final do século XIX e só na metade dos anos 50 é que voltam a ser feitas tentativas de teorização publicadas por educadoras americanas. Estas primeiras teóricas combinavam sua experiência clínica com objetivos educacionais, buscando desenvolver programas de ensino a partir de uma perspectiva de enfermagem e não médica.

ALMEIDA e ROCHA (1989) afirmam que existe uma crise de identidade na enfermagem e que as enfermeiras, através de seu saber, buscam distanciar-se das outras categorias para restabelecer sua identidade. Neste sentido, as teorias de enfermagem são a expressão do saber que as enfermeiras utilizam para estabelecer uma proposta de autonomia.

As teorias de enfermagem, ao buscarem um campo de conhecimento próprio, podem ser um tanto idealizadas, principalmente as importadas de outras realidades. No entanto, são uma proposta de qualificar e tornar representativo o trabalho da enfermagem. Talvez a questão fosse construir teorias mais adequadas à nossa realidade.

Aceitando que as teorias de enfermagem são importantes para o desenvolvimento da profissão devemos lembrar que esta não se constitui apenas de enfermeiras. 
Assim, o conhecimento produzido para a enfermagem não é privativo da enfermeira. Não cabe a enfermeira criar instrumentos de trabalho que serão utilizados por todas as categorias da enfermagem? Desta forma, as teorias precisariam ser ensinadas também nas escolas de técnicos e auxiliares de enfermagem.

Atualmente, na área da educação formal, observa-se a presença crescente de um discurso que defende a formação de uma profissional crítica, com competência política e uma ênfase crescente no que é denominado de saúde pública. ${ }^{6}$ $\mathrm{Na}$ literatura encontra-se também um forte apelo à humanização da assistência e do ensino ao lado de denúncias sobre as condições de trabalho cada vez mais precárias, em especial no setor público.

Concluindo, se a enfermagem é uma prática social, uma profissão, o locus do trabalho com sua lógica não pode ser ignorado, ou seja, o que as instituições empregadoras desejam assim como o que os clientes desejam, e que nem sempre corresponde ao que acreditamos sejam suas necessidades. Assim, a enfermagem sofre o mesmo problema que os trabalhadores em geral, não determina seu trabalho e não possui os instrumentos de trabalho, os quais pertencem aos empregadores.

Por outro lado, a enfermagem tem um compromisso com a sociedade e, neste sentido, deve buscar transformações que melhorem a qualidade de vida desta população. Assim, a construção de um saber que seja instrumento de trabalho deve levar em consideração as condições concretas, o que é, e aquilo que desejamos, o que deveria ser. Neste sentido, concordo com WALDOW (1998) que, se a enfermagem não está totalmente consciente quanto ao que constitui o seu saber e fazer, não há como instituir uma base sólida de profissionalismo.

ABSTRACT: The article presents a theoretical reflection about knowledge as a work tool, and its relationship with the object and finality of the nursing job. With that goal, a brief review of the work process characteristics is presented initially, followed by a discussion of knowledge as a work tool and of the need of it's fitting to the object and job purpose. Finally some considerations on the teaching nursing and its answers to the needs of the profession are presented.

KEY WORDS: Nursing theory; Knowledge; Attitudes; Practice.

6 A expansão do mercado, em particular nos PSF, em parte pode explicar está maior valorização dos profissionais por esta área, anteriormente bastante desprestigiada.

\section{REFERÊNCIAS}

1 ALMEIDA, M.C.P.; ROCHA, J.Y. O saber da enfermagem e sua dimensão prática. 2. ed. São Paulo: Cortez, 1989.

2 ALMEIDA et al. A situação da enfermagem nos anos 80. In: Congresso Brasileiro de Enfermagem, 41, 1989; Florianópolis. Anais do 41 Congresso Brasileiro de Enfermagem, Ed. UFSC, 1989.

3 ALMEIDA, M.C.P.; ROCHA, S.M.M. (Org.). O trabalho da enfermagem. São Paulo: Cortez, 1997.

4 ARGENTA, M.I. Compreender o processo de trabalho da enfermagem: uma necessidade para a profissão. Florianópolis, 2000. Dissertação (Mestrado) - Universidade Federal de Santa Catarina.

5 FREIRE, P. Educação como prática da liberdade. 20.ed. São Paulo: Paz e Terra, 1999.

6 LUNARDI FILHO. O mito da subalternidade do trabalho da enfermagem à medicina. Florianópolis, 1998. Tese (Doutorado) Universidade Federal de Santa Catarina.

7 GEIB, L.G. Educare: ensaiando a pedagogia do cuidado. Florianópolis, 2000. Dissertação (Mestrado) - Universidade Federal de Santa Catarina

8 GONÇALVES, R. B.M. Tecnologia e organização social das práticas de saúde: características tecnológicas do processo de trabalho na rede estadual de centros de saúde de São Paulo. São Paulo: Hucitec Abrasco, 1994

9 LEININGER, M. M. Culture care diversity and universality: a theory of nursing. Nova York: National League for Nursing Press, 1991.

10 LEOPARDI, M.T.;GELBECKE, F.L.;RAMOS, F.R.S. Cuidado: objeto epistemológico da enfermagem? Texto\&Contexto Enfermagem Florianópolis. V.10. n.1, jan./abr. 2001. p.32-49.

11 MARX, Karl. O capital. 8. ed. vol. I. São Paulo: Difel, 1982.

12 MELEIS, A. Theoretical nursing: development and progress. Philadelphia: Lippincott, 1991

13 PIRES, D. Hegemonia médica na saúde e a enfermagem. São Paulo: Cortez, 1989

14 ROSA, M.T. et al. O desenvolvimento técnico-científico da enfermagem - uma aproximação com instrumentos de trabalho. In: Congresso Brasileiro de Enfermagem, 41, 1989, Florianópolis. Anais do $\mathbf{4 1}^{\circ}$ Congresso Brasileiro de Enfermagem. Florianópolis: Ed. UFSC 1989.

15 SILVA, A. L.; RAMOS, F. R. S. As linhas epistemológicas do conhecimento científico. Belém, 2001. Trabalho apresentado no Seminário Nacional de Pesquisa em Enfermagem de 2001.

16 WALDOW, V. Cuidado humano: o resgate necessário. Porto Alegre: Sagra Luzzatto, 1998.
Endereço da autora:

Rua General Câmara, 439 96200-320 - Rio Grande - RS E-mail: cestari@vetorialnet.com.br 